\title{
(Dis)orientation, POV and the Virtual
}

\author{
Mitra Azar
}

Citation: Azar, Mitra. 2021.

(Dis)orientation, POV and the Virtual. Humanities 10: 33. https://doi.org/ 10.3390/h10010033

Received: 16 July 2020

Accepted: 19 January 2021

Published: 23 February 2021

Publisher's Note: MDPI stays neutral with regard to jurisdictional claims in published maps and institutional affiliations.

Copyright: (C) 2021 by the author. Licensee MDPI, Basel, Switzerland. This article is an open access article distributed under the terms and conditions of the Creative Commons Attribution (CC BY) license (https:// creativecommons.org/licenses/by/ $4.0 /)$.
Department of Digital Design and Information Studies, Center for Participatory IT, Aarhus University, 8002 Aarhus, Denmark; azar@cc.au.dk

\begin{abstract}
This essay moves the first steps toward an understanding of the intricate intertwining between the notion of orientation and that of Point of View (POV) across the philosophy of Gilles Deleuze (and in his work with psychotherapist Felix Guattari), and revendicates their crucial role in relation to the concept of the virtual.
\end{abstract}

Keywords: POV; orientation; virtual; center of indetermination; center of envelopment; Leibniz; Bergson; Deleuze

\section{"Which way, which way?" \\ Alice in Wonderland, Louis Carroll}

\section{Deleuze's Virtual, POV and (Dis)orientation: A First Survey}

This essay takes the first steps towards a preliminary understanding of the entanglement between the notions of orientation and that of Point of View (POV) across the philosophy of Gilles Deleuze (and in his work with psychotherapist Félix Guattari), and revendicates their crucial role in relation to the concept of the virtual. As we will see, the notion of POV turns into a vector of differentiation and individuation, and functions as a membrane able to conjure the transformation from the virtual to the actual.

Besides opening the path to a new reading of Deleuze's philosophy, this essay is part of a larger project which aims at building a philosophical architecture capable to investigate the materialist ontogenesis of the concept of orientation through its "adventures" (its polimorphic becoming, or sensible manifold), from Big Bang up to machine vision. At its core, the overall project wants to build a notion of orientation capable of bridging the divide between the organic and the inorganic: from the emergence of orientation in the form of spins (an intrinsic property of elementary particles, rendered mathematically via vectors defined by magnitude and direction), in the realm of physics; to the formation of ecological niches (Umwelten) as oriented fragments of space-time in relation to the organism's Point of View (POV), in the realm of the biological; to the intricate relation between human and (originary) technicity, triggered by bipedism and the changing of the horizon's line as a result of upright orientation, in the realm of evolutionary anthropology; to technologies capable to bridle organic orientation and POVs, in the realm of technics, especially in cinema and computational technology.

At its core, the concept of orientation is a marker of direction between heterogeneous elements, whereas a Point of View (POV) consists in the expression of this directionality. Otherwise said, orientation and POV are one and the same thing: one implies the other so that one is the necessary and sufficient condition for the other. Yet, POV indicates a specific stage in the figure of orientation, namely the moment in which orientation becomes the emergence of a singularity capable to hold, or carry, an orientation in time. This happens when orientation takes (and manages to hold) an inflection: orientation makes a curve, as if attracted by a sort of orientational pool, around a site. The site is the site of expression of the new directionality emerging because of the inflection, and, thus, expresses the POV of the inflection. As we will see, the expression of POV makes a fold at the virtual level, while it unfolds at the actual level. 
The larger investigation behind this essay argues that the riddle of orientation has been put aside by Western philosophy-together with the notion of technics, as shown by Stiegler's philosophy. Stiegler doesn't explicitly realizes how the oblivion of technics happens in parallel to the oblivion of the concept of orientation, although he deals quite explicitly with the notion of disorientation in the second tome of Technics and Time (2009). In fact, the expression "orientation" appears symptomatically in the history of Western philosophy, across epochs and philosophical schools, although it has been rarely (and never comprehensively) treated above board as a philosophical problem, and in its philosophical complexity. In this scenario, it is by looking at the emergence of the concept of orientation in contemporary continental philosophy - and especially by investigating the work of Gilles Deleuze and Bernard Stiegler-that the broader research wants to start in relation to the riddle of orientation, and move backward through the common network of philosophical references. Within this context, this essay represents a preliminary attempt into tracking the notion of orientation in the work of Gilles Deleuze via the Leibniz-Bergson network which Deleuze waves throughout his corpus.

If pages have been written (van Tuinen and McDonnell 2010) about the notion of POV especially concerning Deleuze's work on Leibniz (Deleuze [1988] 1993), it's hard to find critical accounts about the notion of orientation in the work of the French philosopher, let alone an inquiry that deals explicitly and simultaneously with the notion of orientation and its relation to the notion of POV. Furthermore, the work that has been done about Deleuze's understanding of the notion of POV in his The Fold, Leibniz and the Baroque (Deleuze [1988] 1993), has not been waved with in-depth research over Deleuze's books on Cinema, written only a few years before the book on Leibniz, where, rather peculiarly, the notion of POV-quite central in cinematic theory-appears only a few times. Nothing in the Cinema books seems to prepare the ground for Deleuze's interest in the notion of POV, on the contrary, Deleuze gives the impression of tuning down the notion purposely, and mentions it mainly in relation to the work of writer and director Pier Paolo Pasolini, and his literal notion of "free indirect discourse" (Deleuze [1983] 1986a, p. 72), converted into a peculiar use of the cinematic technique of the POV, which he defines as "free indirect subjective" (p. 74). In fact, POV is an acronym coming from the field of cinema, and defines a specific camera movement capable of giving the audience the sensation of being oriented within the filmic space on behalf of the movie characters, somehow "embodying" their orientation in space. We will not dig, here, into the cinematic definition of POV, nor will we show how this definition is central to the develoment of a new theory of POV capable of moving from cinema to new technologies of vision (including AI). Nevertheless, this reference to cinematic POV serves to loosely ground the philosophical definition of POV into something more tangible. In fact, cinematic POV expresses the inflections of a moving body (or a moving POV, or the actor) by reproducing them on screen with an alleged degree of similarity which forces the inflections defining the orientation of another body (usually a seemingly resting POV, or spectator) to tune in to the inflections generated on screen by the camera simulating the inflections of the actor's POV. Thus, it is the attuning between inflections coming from different sites of inflection (actors and spectators) which generate the illusion of overlapping orientations between actor and spectators so as to produce the feeling of embodiment in the spectators. Pasolini's free indirect subjective is a special type of POV where the spectator simultaneously perceives the orientation of the character and that of the camera itself, as if the inflections (or orientations) defining the body-motor schema of the actor coexist with the autonomous inflection of the eye of the camera.

If in the book on Leibniz, Deleuze manages to deal with the concept of POV via Leibniz's concept of the fold, which also implicates that of orientation, it seems possible to say that in the Cinema books Deleuze approaches POV implicitly via Bergson's notion of "center of indetermination" (pp. 62, 64-66) and its relation to directional (centered) and a-directional (a-centered) (pp. 57-64) forms of movement-although the connection 
between POV and Bergson is not really brought forth, mainly because the concept of POV in the Cinema books is rather tangential.

The concept of orientation emerges in Deleuze's somewhat implicit cosmology, as it is outlined in a chapter of A Thousand Plateaus (Deleuze and Guattari [1980] 1987, pp. 39-75), which exposes Deleuze and Guattari's ontology of becoming (or ontogenesis), and through a few paragraphs of Cinema I (Deleuze [1983] 1986a), where Deleuze's cosmological thinking appears more overtly, and yet only sketched very briefly. In his Cinema I, over a few lines, Deleuze traces the process of emergence of the first proto-stable orientation from an isotropic universe, un-oriented because of being uniform in all its orientations with "no point of anchorage nor centre of reference" (Deleuze [1983] 1986a, p. 57). In Bergson's ontology, matter is image and vice-versa: "an atom is an image which extends to the point to which its actions and reactions extend" (p. 58). Nevertheless, matter can be of different kinds (such as organic, or inorganic), and, as a consequence, instantiates in different kinds of images. The constant state of becoming of both organic and inorganic matter characterizes matter as generic movement-image. Deleuze uses Bergson's expression "center of indetermination" to define a type of organic matter, or living image, which emerges from the appearance of gaps between movement-images. For Deleuze, "even at the level of the most elementary living beings one would have to imagine micro-intervals" (p. 63). Within these intervals, a center of indetermination can constitute itself as the emergence of a new orientation within the sea of movement-images. The type of becoming characteristic of movement-images consists in their constant generalized action and reaction "on all their facets and in all their parts" (p. 61), with facets and parts being the result of the process of concretion ${ }^{1}$ of matter: think, for example, about the facets and parts of an atom as the result of the aggregation of simple sub-atomic particles acting and reacting in all their facets and parts. Yet, in the living image, or center of indetermination, the facets and parts are specialized (and not generic, like in the atom): some for action, some for perceiving, some for being affected. As a consequence, the gap generates a center of indetermination or a living image which, in turn, allows movement-images to differentiate into perception-images and action-images. While action-images and perception-images operate at the edges of the gap, the inside of the gap is occupied by affection-images, images that fill the gap "between a perception which is troubling [ ... ] and a hesitant action" (p. 65), turning into a "way in which the subject perceives itself [ ... ] or feels itself from the inside" (p. 65). In short, the center of indetermination is a "living image" (Deleuze [1983] 1986a), a formed biological organism, perceiving, acting, being affected, on the basis of the unique orientation and POV it produces (see Figure 1).

In fact, the notion of orientation appears often under the guise of terms such as "direction(s)" (Deleuze [1983] 1986a, pp. xviii, 12, 32, 61, 63, 69, 70, 73, 86, 118, 123, 124), "directional" (10), or implied by expressions such as "point of inflection" (Deleuze [1988] 1993, pp. 14, 15, 19, 23, 91), "divergent series" (pp. xv, 62, 81, 82, 137), and "convergent series" (pp. 17, 24, 49, 50, 102, 130) in the book Deleuze dedicates to Leibniz. There, the notion of orientation and that of POV are linked somewhat more explicitly via the notion of the fold: the fold is the instantiation of the orientation in terms of inflection (or curve) around a site of inflection called POV. As a consequence, a POV is the expression of an orientation generated by a fold equivalent to the inflection. In this context, nevertheless, only the notion of POV is elevated into a philosophical concept, whereas that of orientation is assumed somewhat naively from Leibniz's formula, which, however, doesn't employ it directly, but certainly gravitates around it. Similarly, in the Cinema books, the concept mainly comes forth either referring to spatial concerns (Deleuze [1983] 1986a), or to the notion of time (Deleuze 1986b), but never in relation to the notion of POV, and not explicitly as orientation, but as a question of "center" and "direction".

1 The expression is used in a Whiteheadian sense, to refer to the process where "the coherence, which the system seeks to preserve, is the discovery that the process, or concrescence, of anyone actual entity involves the other actual entities among its components" (Whitehead 1978, p. 7). 


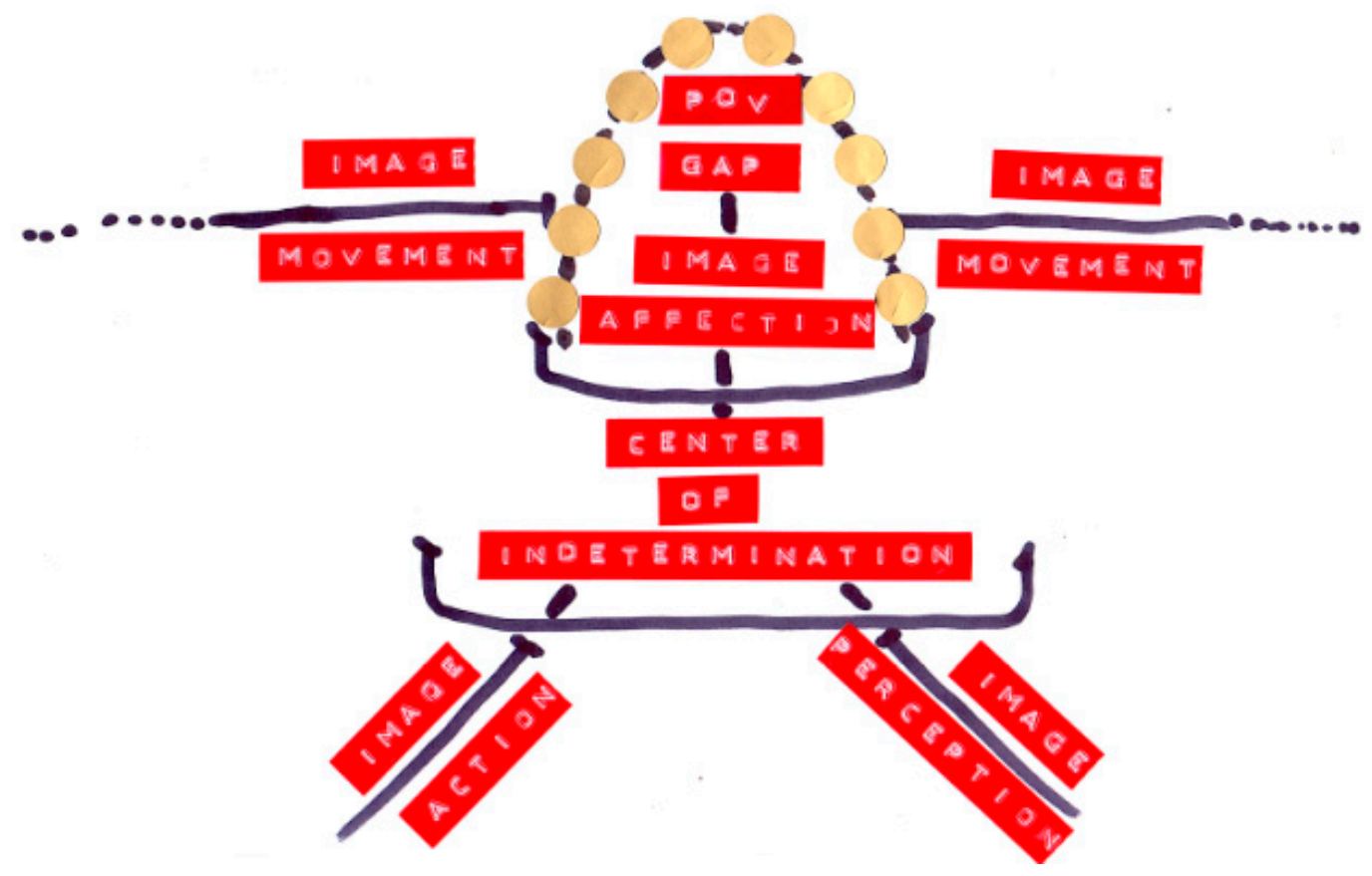

Figure 1. From movement-image to center of indetermination, affect-image, perception-image, action-image.

The wording orientation occurs recurrently only in certain passages of $A$ Thousand Plateaus (Deleuze and Guattari [1980] 1987) in relation to the concepts of territorialization and deterritorialization, with the latter associated explicitly to the word disorientation (Deleuze and Guattari [1980] 1987, p. 196), used only once-not only in this book but throughout Deleuze's corpus. In fact, as we will see, territorialization and deterritorialization verts around the very question of orientation and disorientation (from now on, the simultaneity of orientation and disorientation, which mirrors the simultaneity characterizing the relation between territorialization and deterritorialization, will be addressed with the neologism (dis)orientation). Briefly, if territorialization is a movement characterized by the centered "constancy of orientation" (Deleuze and Guattari [1980] 1987, p. 494), deterritorialization is instead a-centered and traversed by "lines of disorientation" (p. 196) or by "continuous variation in direction" (pp. 486, 488).

The wording orientation is otherwise scattered in Logic of Sense (Deleuze [1969] 1990), where it doesn't receive a properly philosophical treatment, despite the strong influence of Alice in Wonderland (Carroll [1895] 2014), and the explicit reference to Alice's "which way, which way?" - resolved by Deleuze as a question without an answer from the point of view of sense, "since it is the characteristic of sense not to have any direction [italic mine]" (Deleuze [1969] 1990, p. 77). Peculiarly, while the word "direction(s)" recurs often in Logic of Sense, never explicitly thematized in its philosophical potential, "disorientation" is nowhere to be found, although the expression functions quite well as an instrument to understand the imbrication of sense and non-sense in the form of a problem of orientation (direction) and disorientation (directionlessness) - as announced, (dis)orientation. Instead, the word "reorientation" (pp. 130,132) turns up to praise the effort of Stoicism to reorient philosophy at the level of the surface, against "Dyonisus down below" and "Apollo up above" (p. 132). En passant, Deleuze states here something quite profound: on the one side, the history of philosophy is a problem of orientation and, on the other, this history needs to be reoriented, and this new orientation needs to be found at the level of the surface, where the operations of orientation find its expression in the figure of POV that, by functioning as a vector of individuation, catalyzes the transformation of the virtual into the actual.

Few references to orientation appear in Difference and Repetition (Deleuze [1968] 1994) about the need of finding new orientations for the philosophical tradition, while the word direction is central to the book argument and it is poignantly adopted in one occasion 
to explain "how differences become connected and accumulate in a given direction, but also how they tend to diverge further and further in different or even opposed direction" (Deleuze [1969] 1990, p. 248). The numerous implicit and explicit references that the book does to Leibniz reveal Deleuze's early interest over the theme of orientation understood as the differential quality of convergent and divergent directional series-on which we will come back to later on. Furthermore, although Leibniz functions as a reference to the conceptual universe of divergent/convergent series, he is not foregrounded in relation to his concept of the fold, which necessarily implies that of POV. As we've seen before, and we will see in more details later, the fold is an inflection (or curve) around a site of inflection called a POV; without the site of inflection there is no fold, without the process of folding there is no POV. What is idiosyncratic in here is that despite the recurrence of verbal expressions such as folding and unfolding, the nominal locution fold (allegedly the form of what folds and unfolds) is mentioned directly as a focus of inquiry only a few times, although in philosophically strong formulations such as "ontological 'fold" (Deleuze [1968] 1994, p. 64) or when, in a note, Deleuze identifies difference with the fold itself: "this difference [ ... ] it is the fold, Zwiefalt [ ... ] in the double movement of 'clearing' and 'veiling'" (p. 65). In fact, the concept of fold is key to the book although it appears under the guise of another expression, that of "centres of envelopment" (pp. 47, 281, 278, $255,256,261)$. The relation between centers of envelopment and folds, inspired by Leibniz, will help in defining the concept of the monad, an expression the German philosopher uses to identify a point or "a unity that envelops a multiplicity, this multiplicity developing the One in the manner of a series" (Deleuze [1988] 1993, p. 23). Nevertheless, it will take Deleuze twenty years since the publication of Difference and Repetition to directly approach the question of the monad, that of the fold and of POV, in his book on Leibniz, where he will change the monad's constitutive feature from selection and closure to activity and change (Deleuze [1988] 1993). The peculiarity of these centers of envelopment (the very engine of the monad) is that they implicate the "individuating factors" (p. 255) at a stage in which the living, the organic and the inorganic are larval and pre-individual, below the level of formed subjectivity/objectivity (pp. 78, 110), and yet right on the edges of explication into a formed I-Self (p. 257) or object. The centers of envelopment emerge around values of implication, so that "the values of implication are centres of envelopment" (p. 255) in their capacity of orienteering the directional series around fields of individuation. These series develop along lines characterized by sites of inflection which turn the elements of the series into the elements of an inflection which eventually defines a center of envelopment, a fold, and a monad. (see Figure 2).

Already after this quick survey, it seems reasonable to claim that the notion of orientation is never treated above board and as a major concept in Deleuze's philosophy; yet, it recurs constantly within it. In a sense, the lack of critical research on Deleuze's notion of orientation, seems to be symptomatic of the implicit treatment the philosopher dedicates to the concept, which appears recurrently in Deleuze's work but it is never elevated explicitly into a philosophical machine. Otherwise said, if the notion of orientation cuts across the work of the French philosopher, Deleuze himself resists to thematize it undisguised. As a consequence, orientation seems to assume a peculiar status-minoritarian in its explicit treatment, while at the same time pivotal in Deleuze's philosophical work. Even more interestingly, the concept of orientation seems unthinkable in the context of Deleuze's philosophy without its relation to the concept of disorientation, mentioned only once in A Thousand Plateaus, and yet glued onto that of orientation as its shadow-essential to understanding the very meaning of orientation itself, as we will see. Despite Deleuze's feeling concerning the impossibility of finding an answer to Alice's question without incurring into the paradoxes of sense (Deleuze [1969] 1990), we argue that it is the impossibility of thinking orientation without disorientation (which amounts to the possibility of a sense of not having any direction, as Deleuze puts it) that makes Alice's question a properly Deleuzian question, and the figures of orientation and disorientation (in our jargon, (dis)orientation), one of the hidden and most powerful philosophical motor of Deleuze's philosophy. 


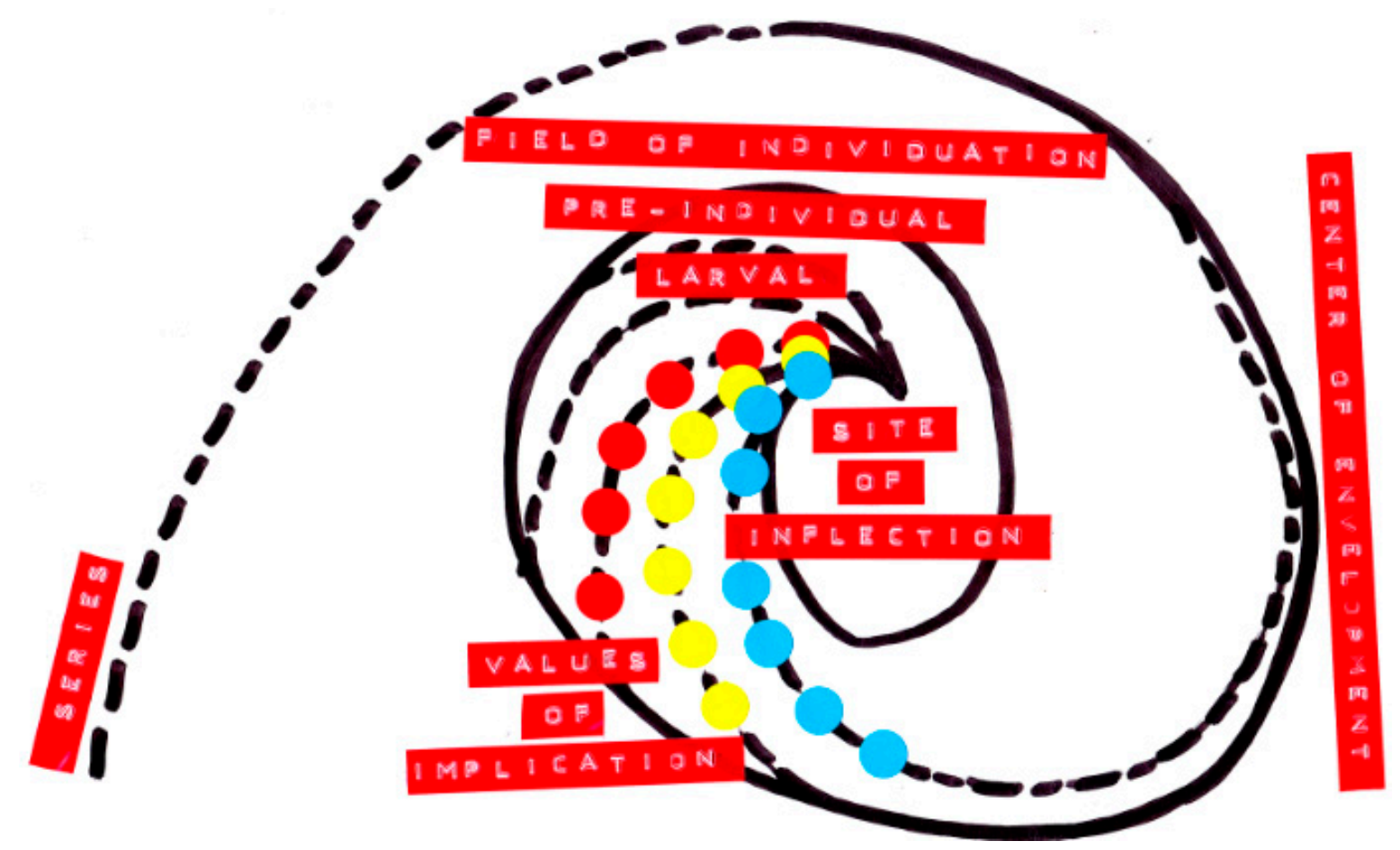

Figure 2. Center of envelopment, site of inflection, Point of View (POV).

In this context, a parallel analysis of Deleuze's treatment of Leibniz's fold and Bergson's center of indetermination seems to be a good starting point to understand the role of orientation and POV in Deleuze's philosophy. For us, the implicit element connecting Bergson, Leibniz, and Deleuze's philosophy is the notion of orientation. Thus, under this philosophical perspective, the passage from the virtual to the actual resolves in a problem of orientation and disorientation ((dis)orientation), and the notion of POV plays the role of both the catalyzer and transformer of this passage. In short, POV folds into the expression of a virtual orientation coming from a point or site of inflection - the one which identifies Leibniz's center of envelopment-and unfolds through its inclusion into Bergson's center of indetermination, which produces also its actualization. Bluntly put, to bridge Leibniz and Bergson means trying to think the inflection or implication of Leibniz's center of envelopment around a POV and the inclusion or explication of that very POV inside Bergson's center of indetermination. To put it another way, as we will see, it seems there are two states of POV: one which appears at the level of the center of envelopment-which is at the level of the virtual, before actualization - and the other at the level of the center of indetermination, or actual level. In fact, one state of POV turns into the other, such that the POV of a center of indetermination functions as the actual site of expression for the POV of a center of envelopment which, in turn, works as a virtual site of inflection for the latter. Otherwise said, POV as the site of inflection for a center of envelopment turns into POV as the site of expression for a center of indetermination. Schematically, Leibniz's center of envelopment is constituted around a site of inflection (POV-catalyzer), while Bergson's center of indetermination is constituted around a site of expression (POV-transformer). POV catalyzer and POV transformer are the two facets, virtual and actual, of POV. If the POV of a center of envelopment manifests at the level of the virtual, its transformation into the POV of a center of indetermination corresponds to its passage into the actual, which happens at the level of Bergson's living image, or center of indetermination:

"we are moving from inflection to inclusion in a subject, as if from the virtual to the real, inflection defining the fold, but inclusion defining the soul or the subject, that is, what envelops the fold, its final cause and its completed act" (Deleuze [1988] 1993, p. 23). 
Simply put, the passage from the virtual to the actual is a consequence of the capture of the POV or site of the center of envelopment by the center of indetermination.

Both Leibniz's center of envelopment and Bergson's center of indetermination are characterized by the presence of affective qualities. For Leibniz, the affective qualities of micro-perceptions compose the obscure molecular folding of the monad, and constitute the fabric of the monad's POV. For Leibniz, a point of view is "not exactly a point but a place, a site" (p. 19). In reality, the word "view" is, in fact, also misleading: for Leibniz, POV is the site of the monad's micro-perceptions "made from an infinity of tiny folds (inflections) endlessly furling and unfurling in every direction" (Deleuze [1988] 1993, p. 86), folds in folds, over folds, following folds" (Deleuze [1988] 1993, p. 86). These "obscure confused perceptions [ ... ] make up our macroperceptions", and a "subject will be what comes to the point of view, or rather what remains in the point of view" (p. 19). In fact, the passage from virtual micro-perception composed by affective qualities to actual macro-perception happens at the threshold between Leibniz's center of envelopment and Bergson's center of indetermination, where a POV emerges as a figure of implication in a center of envelopment (POV-catalyzer), and inclusion in a center of indetermination (POV-transformer). In short, POV functions as the virtual site of inflection of a center of envelopment, but also as the site of expression and explication (actualization) of a center of indetermination. (see Figure 3).

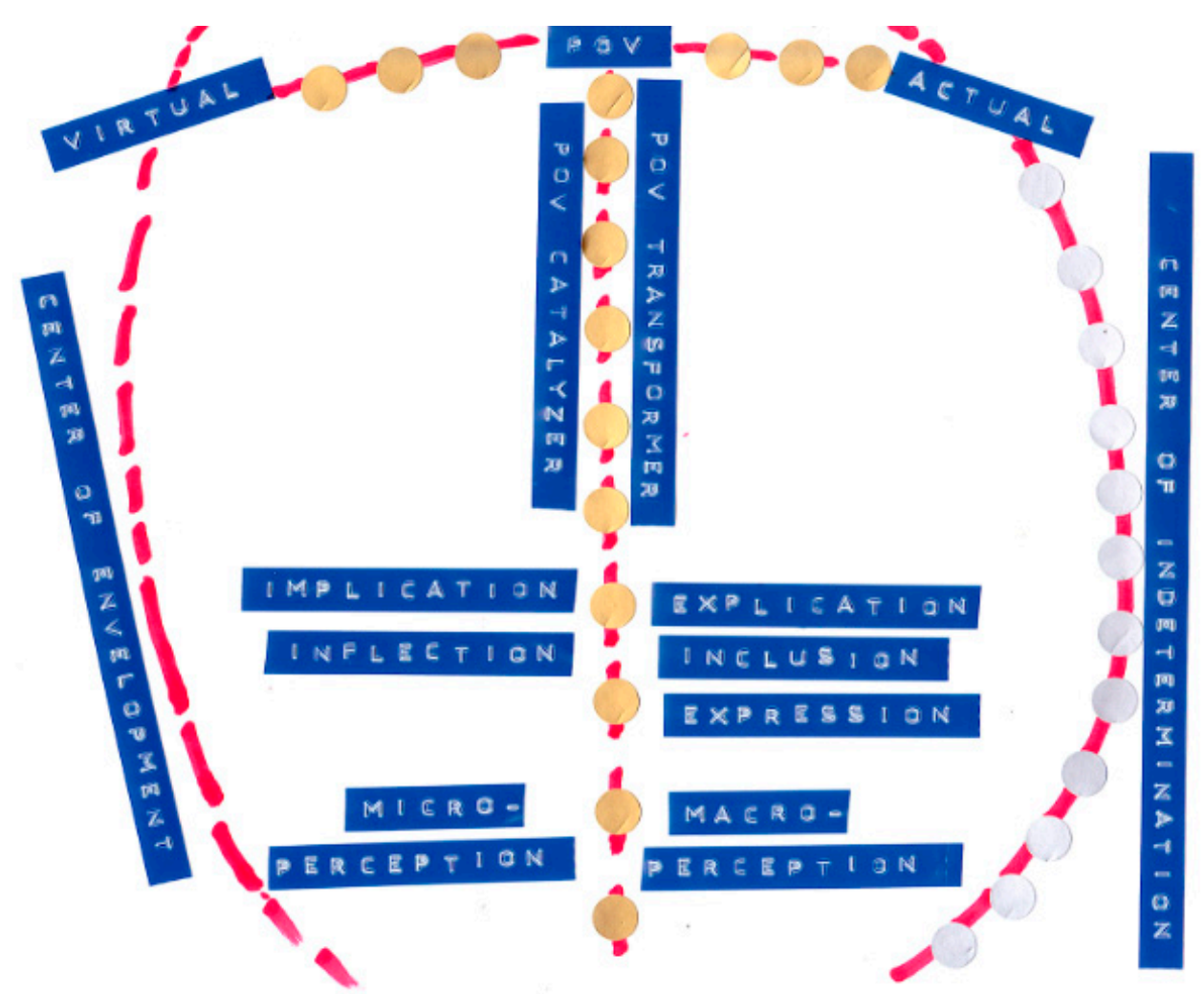

Figure 3. Center of envelopment and center of implication between POV-catalyzer and POV transformer.

\section{2. (Dis)orientation and POV: Bergson and Deleuze's Cosmo-Ontogenesis}

In Cinema I, Deleuze seems to give a cosmological twist to some of the central ideas of A Thousand Plateaus, and the physical state of the early universe functions here as a sort of physical manifestation of the smooth plane of immanence composed by a-centered and disoriented flowing matter. A matter composed by free-floating singularities in which no point of anchorage nor center of reference would be assignable (p. 57), and characterized by the constant and unstable differential change of orientation and speed: "a plane of immanence [ ... ] upon which unformed elements and materials dance [and] are distinguished from one another only by their speed and [ ... ] their relation of movement" 
(p. 255) - a movement defined, as we will see by reading Bergson together with Leibniz, by simultaneous orientation and disorientation, or (dis)orientation. Thus, Deleuze's cosmology is peculiarly approached in his Cinema I-The Movement-Image (Deleuze [1983] 1986a), the first book the French philosopher dedicates to cinema, followed by Cinema II-The Time-image (Deleuze 1986b). In Cinema I, the philosopher sketches his ontology in properly cosmological terms by proposing to think about the universe as a meta-cinema. Deleuze's attempt emerges from a close and controversial reading of Matter and Memory by Henri Bergson (Deleuze [1988] 1993). Bergson thinks "cinema misconceives movement [ ... ] in the same way of natural perception and for the same reasons: 'we take snapshots, as it were, of passing reality'" (Deleuze [1983] 1986a, p. 57). In Creative Evolution, Bergson refers to the "cinematographic illusion" (p. 1) as the (illusory) generation of movement from "two complementary given: instantaneous sections which are called images: and a movement or a time which is impersonal, uniform, abstract, invisible, or imperceptible, which is in the apparatus" (p. 2)-the apparatus being either cinema or the subject of natural perception. That's why, for Bergson,

"the model [of perception] cannot be [the cinematographic model of] natural [italic mine] perception, which does not possess any privilege, [but] a state of things which would constantly change, a flowing-matter in which no point of anchorage nor center of reference would be assignable" (Deleuze [1988] 1993, p. 57).

By proposing to think about the universe as a meta-cinema, Deleuze turns upside down Bergson's criticism, and recasts cinema as the cosmological process through which solid oriented matter emerges from "flowing-matter". From the "cooling down of the plane of immanence [in the cosmology of the Big Bang, the cooling down of the quantum fluctuations], [ ... ] the first opacities, the first screens obstructing the diffusion of light" (Deleuze [1983] 1986a, p. 63) in the form of solid matter, allows the formation of more solid matter, in an accelerating process of concretion. In this sense, Deleuze's notion of cinema escapes from the limits of natural perception, and turns Bergson's cosmology into a meta-cinematic machine composed by image(s)-movement (p. 58) constituting a plane of immanence of flowing-matter, or Bergson's "acentred universe of movement-images" (p. 62) which "act and react on all their facets [in all directions] and in all their parts" (p. 61):

"everything [ ... ] is indistinguishable from its actions and reactions: this is universal variation. Every image is 'merely a road by which pass, in every direction, the modifications propagated throughout the immensity of the universe'" (p. 58).

From these conditions, chunks of matter start to cluster turning directionlessness into dimension(s) giving raise to striatures of various kind, from crystal of matter to biological "centre of indetermination" (p. 62). The expression "centre of indetermination" (p. 62), borrowed from Bergson, recurrent in Cinema I, refers to the living images "which are formed in the acentred universe of movement-images", and which emerge from "the gap, or the interval between a received and an executed movement" (p. 62). Thus, from a universe of disoriented and directionless movement-images acting and reacting on all their facets and in all their parts, Deleuze introduces the perception-image. The perception-image refers to a type of image which "only receive[s] actions on one facet or in certain parts and only execute[s] reactions by and in other parts" (p. 62). It's within this process that living center of indetermination emerges from the interval, together with perception: "the image reflected by a living image is precisely what will be called perception" (p. 62).

"The thing is the image as it is in itself, as it is related to all the other images to whose action it completely submits and on which it reacts immediately. But the perception of the thing is the same image related to another special image which frames it, and which only retains a partial action from it" (Deleuze [1983] 1986a, p. 64). 
Perception happens in the interval, and expresses the "coming to the point of view" (Deleuze [1988] 1993, p. 19) occupied by the center of indetermination. Otherwise said, $\mathrm{POV}$ is the form of the interval in terms of orientation. Orientation emerges as the capability of living images to occupy a gap between action and reaction. Between the directionless and disoriented constant action/reaction of the movement-images, the emergence of intervals in the fabric of movement opens the space for the constitution of organic living matter characterized by distinctive orientations. Intervals define living images and their orientation within what von Uexküll calls Umwelten:

"everything a subject perceives belongs to its perception world [Merkwelt], and everything it produces, to its effect world [Wirkwelt]. These two worlds, of perception and production of effects, form one closed unit, the environment [Umwelt]" (von Uexküll 2010, p. 42).

Reading von Uexküll through Deleuze and Bergson allows us to think about perception and production as the two limit facets of the interval. The interval produces a curve- or an inflection, in Leibniz's words: "by incurving, perceived things tender their unstable facet towards me, at the same time as my delayed reaction, which has become action, learns to use them" (Deleuze [1983] 1986a, p. 64). Deleuze introduces here the action-image, and describes both perception-image and action-image as the "specialization of the two limit-facets, perceptive and active", of the gap or interval: in fact, "perception is only one side of the gap, and action is the other side" (p. 64). Nevertheless,

"the interval is not merely defined by the specialization of the two limit-facets, perceptive and active. There's an in-between. Affection is what occupies the interval, what occupies it without filling it in or filling it up" (p. 65).

For Bergson, there is no perception without affection (Bergson 1988, pp. 17-76). Affection happens

"between a perception which is troubling in certain respects and a hesitant action.

It is a coincidence [ ... ] in which the subject perceives itself, or rather experiences itself or feels itself 'from the inside'" (Deleuze [1983] 1986a, p. 65).

Thus, a larval Umwelt begins to take shape already at the level of the interval between action and reaction, where an orientation or a POV emerges. Bergson's image-perception functions as the expressive manifestation of the POV occupied by a center of indetermination emerging from the interval between action and reaction, an interval which produces, together with an image-affection, an image-perception, and a (biological) orientation within an Umwelt, culminating in an image-action (based on the Umwelt's affordances). Bergson's center of indetermination becomes the site of unfolding of the POV folded in the gap, the site where affection turns into perception and orientation and, eventually, into action (see Figure 1).

\section{From Leibniz's Monadology to Deleuze's Nomadology: Series and Chaosmos}

In Deleuze's view, at the level of Leibniz's center of envelopment, Umwelt is still a Welt, or a "chaosmos [ ... ], a multiplicity unbound from any pre-established and fully individuated order (van Tuinen and McDonnell 2010, p. 173). The POV of a center of envelopment is larval and pre-individual. If this allows the monad to be "pregnant" (Strickland 2014, p. 4) with futures, it also prompts the monad's POV to generate a center of envelopment capable of constituting a larval orientation toward these futures, a larval ability of framing them in a given sense, or inflection. POV catalyzes the production of an orientation at the virtual level of the center of envelopment. This orientation gets included inside a center of indetermination, where the monad's POV becomes fully expressive. Let's here note that for Leibniz, POV is already expressive at the level of the center of envelopment, although what we claim here is that the expression of POV at the level of the 
center of indetermination is an expression that happens at the level of the actual, while the other stays at the level of the virtual ${ }^{2}$.

As we've seen in the introduction, center of envelopment is a recurrent expression in Leibniz's Monadology, and Deleuze uses it to refer to the folding up of the space of singularities according to the "law of folds or changes of direction" (Deleuze [1988] 1993, p. 12) via points of inflection, or elastic points, or points-fold (p. 14). As stated before, POV as a site of inflection catalyzes the constitution of an orientation, and, as a consequence, of center of envelopment, which acts as the site of constitution—or the genetic element—of Leibniz's monad. Deleuze's monad is very different from Leibniz's one. The virtual, larval, pre-individual status of the monad and its individuating factor (site of inflection or POV, and center of envelopment) allows Deleuze to overcome its closure. If the monad's closure is one of the defining features of the monad according to Leibniz, Deleuze's reverse closure into action and change, in short, in favor of its becoming. At the level of the chaosmoswhich means at its virtual stage-this becoming cannot support closure without losing its very processual status, and consists of an open network constituted by the simultaneous compossibility and incompossibility of the series of singularities (Deleuze [1969] 1990). This means that the points of a series are tipping in all directions at the same time, diverging and simultaneously converging. From this condition, the series composed by singularities manage to aggregate around "'not exactly a point but a place, a position, a site" (Deleuze [1988] 1993, p. 19) of inflection where "these impersonal and pre-individual nomadic singularities" (p. 109) converge, eventually polarizing around a "center of envelopment [... ], as enveloping singularities inside a world [Welt]" (p. 111), which is not yet an Umwelt. Via Leibniz, Deleuze calls this site of polarization a Point of View (POV), in fact, rather a site of inflection in the form of an "intrinsic singularity" (p. 15), implicating the center of envelopment. In this genetic context, and in light of Deleuze's cosmo-ontological architecture, it is possible to force the closure of Leibniz's "monad without windows" (Deleuze [1988] 1993, p. 26).

For Deleuze, the universe is a chaosmos (Deleuze [1968] 1994, [1969] 1990, [1988] 1993; Deleuze and Guattari [1980] 1987). Yet, chaos "is not without its own directional components, which are its own ecstasies" (Deleuze and Guattari [1980] 1987, p. 313), and these ecstasies are singularities characterized by a movement akin to that of Bergson's universe of movement-images, a movement in all directions at the same time, simultaneously diverging and converging. It is within this movement that singularities from different series cluster around sites of inflection or POVs as if around values of implication capable of producing a feeble yet meta-stable orientation, in the form of a center of envelopment, which cuts through the homogeneous becoming of movement-images, acting and reacting in "all their facets and parts". In a world "made up of divergent series (the chaosmos)" (Deleuze [1988] 1993, p. 137), a site of inflection generates a center of envelopment understood as a new orientation or divergency, constituted by the convergency of singularities from different series around a site of inflection, or POV. This emerging divergency, which was neither pre-existing nor predictable, stands as a larval form of organization in the chaos of movement-images, or chaosmos. Once more, this is the result of the accidental clustering of singularities distributed over different series pulled together by the POV or site of inflection of the center of envelopment. The orientational pool performed by the site of inflection over the chaotic divergency and convergency of the series (or movement-images) produce the passage from unconnected and free floating differences which diverge and converge seamlessly in a pure omnidirectional chaos, to the inflection of the series around centers of envelopment, constituted by the temporary convergence and compossibility of singularities located over divergent series, around a site of inflection, a POV, an orientation. To be clear, the convergence of singularities located over divergent series, produce a new orientation understood as a new divergence-a divergence constituted by the convergency

2 For reasons of space, we will have to skip the question of the monad's POV as mirrored perception (Strickland 2014), as well as Bergson's understanding of perception as already expression (Bergson 1988). The bridging between Bergson and Leibniz via Deleuze passes through the figure of the mirror and an understanding of perception as expression. 
of divergent series. This is why divergence and convergence, as much as orientation and disorientation, happens simultaneously.

Against Leibniz's "new harmony" (Strickland 2014), monads and POVs inhabit a chaosmos, and "the monad is [ ... ] unable to contain the entire world as if in a closed circle" (Deleuze [1969] 1990, p. 137), and tends to spiral "further and further away from a center" (p. 137). As a consequence, the monad's POV functions always as an "ex-centric center" (Deleuze [1969] 1990, p. 176), a "center of convergence [ . . ] by nature perpetually decentered" (p. 174), converging to "affirm divergence" (p. 175) and diverging to affirm convergency. This is happening because the orientational pool performed by the site of inflection works against the pools coming from the points or singularities located on the series which diverge and which weave the fabric of a world (Welt), and not yet an Umwelt. In fact, the Umwelt appears as the result of the inclusion of a center of envelopment into a center of indetermination. Thus, the POV of a center of indetermination is the actualization of the POV of a center of envelopment, and expresses itself in relation to the affordances available within the center of indetermination's ecological niche, or Umwelt, and according to the Bergsonian reading of von Uexküll sketched in the previous section.

Leibniz's monadology turns into a nomadology through which it is possible to transform Leibniz's perspectivism built upon monades without windows, into a flux of becoming characterized by a perspectivism of sites of singularities which generates POVs capable to cut across the virtual and the actual, and to function as a membrane between them. Given these premises, bridging Deleuze's reading of Bergson and Leibniz means thinking the notion of POV as an elastic membrane between Leibniz's center of envelopment and Bergson's center of indetermination. While in Deleuze's view, the POV sits below the folding of the irregular curving of the series, as a virtual point of inflection, we suggest that the expression of the POV's center of envelopment happens on the curve: the curve serves as the site of expression of the POV, and the consistency of the curve is that of a surface, a membrane, where internal (center of envelopment) and external (center of indetermination) meet—in other words, the skin of the POV. (see Figure 4)

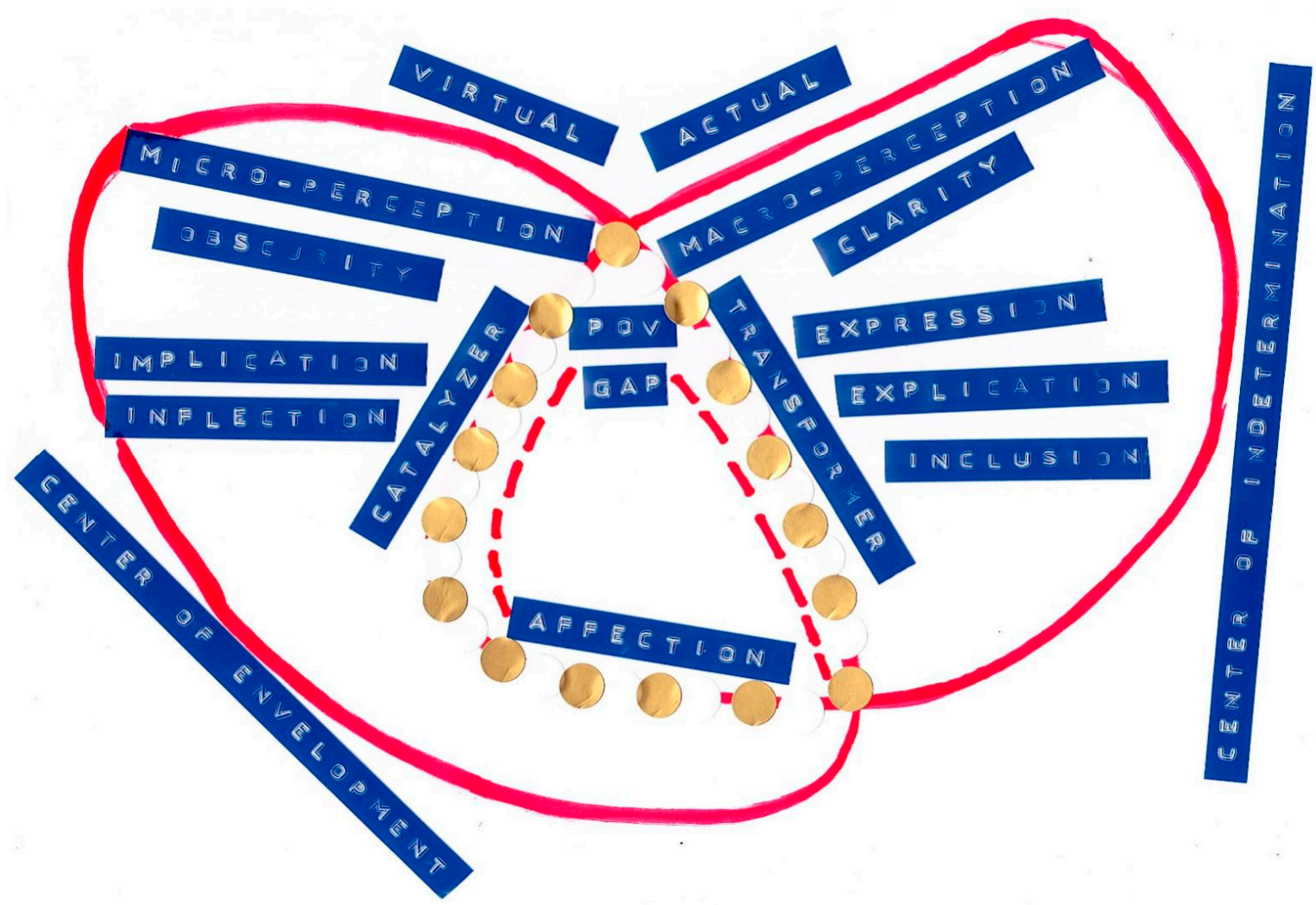

Figure 4. Center of envelopment and center of indetermination between virtual and actual. 
In this sense, we argue that if the POV is the active expression of the monad, its activity happens on the curve, and the curve taking form around the point of inflection functions as the expressive membrane of its POV. In this form, the POV expresses itself on the curve or membrane as a bridge between actual and virtual. The expressive quality of $\mathrm{POV}$ on the curve allows the transformation of a center of envelopment into a center of indetermination in a way that the letter maintains a degree of indeterminacy, or virtuality, which allows its becoming. This way of reading Deleuze's understanding of Leibniz and Bergson, foregrounds the role of the concept of POV and its relation to the concept of (dis)orientation implicit in Deleuze's philosophy.

\section{4. (Dis)orientation, Territorialization and Deterritorialization between Center of Envelopment and Center of Indetermination}

In Bergson, a center of indetermination emerges around a gap within the structure of matter understood as a sea of movement-images. Thus, from the movement-image, the perception-image unfolds together with the affection-image, right at the interval between the constant action and reaction of movement-images. Centers of indetermination proliferate and "even at the level of the most elementary living beings one would have to imagine micro-intervals. Smaller and smaller intervals between more and more rapid movements" (Deleuze [1983] 1986a). In Leibniz, the question of the micro-interval turns into the question about how "obscure confused [ ... ]micro-perception [ . . ] in every direction" give shape to "conscious, clear and distinct apperceptions" (Deleuze [1988] 1993, p. 86), or macro-perception, here understood as the "production of differential relations that are established among micro-perceptions" (p. 94). It is interesting to notice how where Leibniz thinks about micro-perception, Bergson thinks about micro-interval, so that where for Bergson the question of POV is mainly a question of time, for Leibniz it is a question of site, of position - that is, of point of view (p. 20).

For Leibniz, the micro-perceptions folded into the centers of envelopment are the 'affective qualities' (Deleuze [1988] 1993, p. 96) of the monad, implicated in its obscure folds, and constituting a passive ground of becoming. As pointed out, in Leibniz, "perceptions are conceived in terms of a quantitative difference in size [against micro-perceptions], thus designating the two dimensions in scale to which Leibniz assigns active and passive forces" (van Tuinen and McDonnell 2010, p. 78). We would like to argue that Leibniz's macro-perception expresses the active forces at work at the level of Bergson's center of indetermination, and emerge as the transformation of Leibniz's passive micro-perceptions, at work at the level of the center of envelopment. Furthermore, bridging Deleuze's reading of Bergson and Leibniz means understanding the spiraling out of the monad from its ex-centric center (the center of envelopment, which gravitates around the monad's POV) as the result of the hollowness of this very center. In Bergson's term, the center is, in fact, a gap. The center is hollowed because the center is not a center, but a site in Leibniz's sense (an ex-centric site of inflection). The site is characterized by a Bergsonian's gap-a gap which is not empty but filled with affective qualities arranged according to the divergence and convergence of the series in relation to their folding and unfolding over lines of variable inflections, and to the orientational pool exercised by the site of inflection. The paradox is that from a gap of view between the sea of movement-images, a POV emerges. This is because the gap is not empty, rather it is traversed by affects aggregating around points of inflections.

In this cosmo-ontogenetic context, which we've argued to rely on the notion of (dis)orientation, the concepts of territorialization and deterritorialization could serve as the conceptual couple that better frames Deleuze's understanding of (dis)orientation, and function as a bridge between the cosmo-ontological field and the biological, aesthetic, and more properly human and political field of Deleuze's philosophy. (Dis)orientation is a vector of territorialization (striate space) and deterritorialization (smooth space). In fact, if territorialization is characterized by the centered "constancy of orientation" (Deleuze and Guattari [1980] 1987, p. 494) within "closed intervals" and "extensive dimensions" where "the line is between two points" (p. 481), deterritorialization is a-centered and traversed by 
flat "lines of disorientation" or by "continuous variation in direction" (p. 486) within "open intervals" in which the "point is between two lines" (p. 481) and "the ground constantly changes direction" (p. 574). In fact, both territorialization and deterritorialization are folded into each other in a way that territorialization needs deterritorialization, and vice-versa.

Using this new jargon, we could say that POV deterritorializes in a center of envelopment and territorializes in a center of indetermination. In so doing, POV acts as a transformer of a center of envelopment into a center of indetermination. POV has two facets: the virtual facet of POV acts as a site of inflection for a center of envelopment (POV catalyzer), whereas its actual facet acts as the site of expression of a center of indetermination (POV transformer). Its two facets, the virtual and the actual, constitute the ontological limits of the gap from where a POV emerges. It's in the gap that the center of indetermination includes the center of envelopment. "A gap is opened which makes the envelope the reason for the fold", because "what is folded is only virtual and currently exists only in an envelope [actual], in something that envelops" (Deleuze [1988] 1993, p. 22). POV runs over the virtual/actual circuit while bridging the fold with the envelope, the center of envelopment with the center of indetermination. In so doing, POV turns into a "site of cosmogenesis", a "nondimensional [virtual] point, between dimensions" (p. 15). The dimensions of the virtual and the actual are the dimensions of inflection and inclusion: "we have gone from variable curvature [ ... ] to point of view, from the fold to envelopment, in a word, from inflection to inclusion" (p. 22). For Bernard Cache, the inflection is an "Event of the line or of the point, the Virtual" (p. 15). In other words, Bergson's gap accommodates Leibniz's site of inflection and functions as a "pre-individual field, a virtual [ ... ] field, made up of differential relation" (Deleuze [1968] 1994, p. 246) between affect-images, "emissions of singularities insofar as they occur [ ... ] through a nomadic distribution, radically distinct from fixed and sedentary distributions as conditions of the syntheses of consciousness" (Deleuze [1969] 1990, pp. 102-3), which instead happen at the actual level of the center of indetermination.

The actual and the virtual form an image which is, above all, a site understood as an orientation, and this orientation, as we've seen, is in fact (dis)orientation. The very notion of POV we adapted from Leibniz passing through Deleuze, can turn into a special type of image in Bergson's ontology: the POV-image. Given that the facets of this image are both actual and virtual, this image is what Bergson calls a "crystal-image" (p. 69), a figure of thought introduced to describe the functioning of the actual/virtual circuit. POV-image is a crystal also because "crystal is an expression" (p. 74), and POV-image expresses a (dis)orientation within a virtual/actual circuit where virtual and actual acts as the limit facets of the image. (Dis)orientation defines the processes of deterritorialization and territorialization this image is traversed by at the level of the center of envelopment where it is implicated, and at the level of the center of indetermination where it is included, or explicated. The POV-image bridges over the gap between the center of envelopment and the center of indetermination, between virtual and actual. If the virtual facet of the POV-image corresponds to the affection-images or the affective qualities which constitute the micro-perceptions occupying the center of envelopment, the actual facet transforms them into macro-perceptions for a center of indetermination ${ }^{3}$.

\footnotetext{
3 There is an important difference here between Bergson and Leibniz. For Bergson, the virtual is in the part, the part being the center of indetermination - or, we can say, one of the facets of the POV which the center of indetermination occupies. The (dis)orientation of a center of indetermination is defined both by a process of framing — constituting the image-perception — and a process of incurving — during which, as we've seen, "perceived things tender their unstable facet towards me" (Deleuze [1983] 1986a, p. 64), allowing "the virtual action of things on us and our possible action on things" (p. 65). In other words, "the more the reaction ceases to be immediate and becomes truly possible action, the more the perception becomes distant and anticipatory and extracts the virtual action of things" (p. 65). Framing and incurving are "distinct, but indiscernible, such are the actual and the virtual which are in continual exchange" (Deleuze 1986b, p. 70): this is because perception (framing) is already expression (incurving). For Leibniz, the virtual stays in the whole, while the actual in the part, in a dynamic in which "the world must be placed in the subject in order that the subject can be for the world. This is the torsion that constitutes the fold of the world and of the soul" (Deleuze [1988] 1993, p. 26). In this torsion, "subjects all relate to this world as if to the virtuality they actualise'" (van Tuinen and McDonnell 2010, p. 172): thus, "if the world is in the subject, the subject is no less for the world" (Deleuze [1988] 1993, pp. 25, 50) or, otherwise said, "[t]he soul is the expression of the world (actuality), but because the world is what the soul expresses (virtuality)' (Deleuze [1988] 1993, p. 26).
} 
The convergence and divergence of the series according to the (dis)orientation of the POV and its (de)territorialization between centers of envelopment and centers of indetermination, provide a fertile ground to explore Bergson and Leibniz's resonances in light of Deleuze's ontogenesis and larval cosmology. This approach could help to highlight the implicit role of (dis)orientation and POV in the passage from the virtual to the actual in Deleuze's philosophy, which, for mysterious reasons, has been unexplored until now. Furthermore, the essay feeds the larger research project aiming at exploring the symptomatic appearances of the notion of orientation in contemporary Western philosophy as traces of the oblivion of the figure of orientation in the history of Western philosophy itself.

Funding: This research received no external funding.

Conflicts of Interest: The author declares no conflict of interest.

\section{References}

Bergson, Henry. 1988. Matter and Memory. New York: Zone Book.

Carroll, Lewis. 2014. Alice in Wonderland. New York City: Macmillan. First published in 1895.

Deleuze, G. 1986a. Cinema I. The Movement-Image. Minneapolis: University of Minnesota Press. First published 1983.

Deleuze, G. 1986b. Cinema II. The Time-Image. Minneapolis: University of Minnesota Press.

Deleuze, G. 1990. Logic of Sense. New York: Columbia University Press. First published 1969.

Deleuze, G. 1993. The Fold. Leibniz and the Baroque. London: The Athlone Press. First published 1988.

Deleuze, G. 1994. Difference and Repetition. New York: Columbia University Press. First published 1968.

Deleuze, G., and Félix Guattari. 1987. A Thousand Plateaus. Capitalism and Schizofrenia. Minneapolis: University of Minnesota Press. First published 1980.

Strickland, L. 2014. A New Translation and Guide. In Monadology. Edinburgh: Edinburgh University Press. van Tuinen, S., and N. McDonnell. 2010. Deleuze and the Fold: A Critical Reader. New York: Palgrave Macmillan. von Uexküll, J. 2010. A Foray into the Worlds of Animals and Humans. Minneapolis: University of Minnesota Press. Whitehead, Alfred North. 1978. Process and Reality. New York: The Free Press. 